\title{
Coupled Coincidence Point Theorems for New Types of Mixed Monotone Multivalued Mappings in Partially Ordered Metric Spaces
}

\author{
Chalongchai Klanarong and Suthep Suantai \\ Department of Mathematics, Faculty of Science, Chiang Mai University, Chiang Mai 50200, Thailand \\ Correspondence should be addressed to Suthep Suantai; suthep.s@cmu.ac.th
}

Received 19 June 2013; Accepted 15 September 2013

Academic Editor: Chi-Ming Chen

Copyright (C) 2013 C. Klanarong and S. Suantai. This is an open access article distributed under the Creative Commons Attribution License, which permits unrestricted use, distribution, and reproduction in any medium, provided the original work is properly cited.

\begin{abstract}
We introduce and study new types of mixed monotone multivalued mappings in partially ordered complete metric spaces. We give relationships between those two types of mappings and prove their coupled fixed point and coupled common fixed point theorems in partially ordered complete metric spaces. Some examples of each type of mappings satisfying the conditions of the main theorems are also given. Our main result includes several recent developments in fixed point theory of mixed monotone multivalued mappings.
\end{abstract}

\section{Introduction and Preliminaries}

Let $(X, d)$ be a metric space, and let $C B(X)$ be the class of all nonempty bounded and closed subsets of $X$. For $x \in X$ and $A \subseteq X$, we denote $d(x, A)=\inf \{d(x, y): y \in A\}$. For $A, B \in C B(X)$, define

$$
\delta(A, B)=\sup \{d(x, y): x \in A, y \in B\} .
$$

If $A=\{a\}$, then we write $\delta(A, B)=\delta(a, B)$. Also in addition, if $B=\{b\}$, then $\delta(A, B)=d(a, b)$. For all $A, B, C \in C B(X)$, the definition of $\delta(A, B)$ gives the following formulas:

(i) $\delta(A, B)=\delta(B, A)$;

(ii) $\delta(A, B) \leqslant \delta(A, C)+\delta(C, B)$;

(iii) $\delta(A, B)=0$ if and only if $A=B=\{a\}$;

(iv) $\delta(A, A)=\operatorname{diam}(A)$.

It is easy to see that the following inequality holds, for $x, y \in X$,

$$
|d(x, A)-d(y, A)| \leqslant d(x, y),
$$

for all $A \subseteq X$. By using the above inequality, the following lemma is obtained.
Lemma 1. Let $X$ be a metric space, and let $A$ be a nonempty subset of $X$. If $g$ is defined by

$$
g(x)=d(x, A), \quad \forall x \in X,
$$

then $g$ is continuous.

Let $X$ be a nonempty set, $F: X \times X \rightarrow 2^{X}$ (collection of all nonempty subsets of $X$ ), and $g: X \rightarrow X$. An element $(x, y) \in X \times X$ is called

(i) coupled fixed point of $F$ if $x \in F(x, y)$ and $y \in F(y, x)$,

(ii) coupled coincidence point of a hybrid pair $\{F, g\}$ if $g(x) \in F(x, y)$ and $g(y) \in F(y, x)$,

(iii) coupled common fixed point of a hybrid pair $\{F, g\}$ if $x=g(x) \in F(x, y)$ and $y=g(y) \in F(y, x)$.

We denote the set of coupled coincidence point of mappings $F$ and $g$ by $C(F, g)$. Note that if $(x, y) \in C(F, g)$, then $(y, x)$ is also in $C(F, g)$.

The hybrid pair $\{F, g\}$ is called w-compatible if $g(F(x, y)) \subseteq F(g(x), g(y))$ whenever $(x, y) \in C(F, g)$. The mapping $g$ is called $F$-weakly commuting at some point $(x, y) \in X \times X$ if $g^{2}(x) \in F(g(x), g(y))$ and $g^{2}(y) \in F(g(y), g(x))$. 
Let $(X, \leqslant)$ be a partially ordered set, and suppose that there is a metric $d$ on $X$ such that $(X, d)$ is a metric space. For $x, y \in X$, we write $x<y$ if $x \leqslant y$ and $x \neq y$. On the product space $X \times X$, we consider the following partial order:

$$
\begin{gathered}
\text { for }(x, y),(u, v) \in X \times X, \\
(u, v) \leqslant(x, y) \Longleftrightarrow x \geqslant u, y \leqslant v .
\end{gathered}
$$

The existence of a fixed point for contraction type of mappings in partially ordered metric spaces has been considered recently by Ran and Reurings [1], Gnana Bhaskar and Lakshmikantham [2], Nieto and Rodríguez-López [3, 4], Agarwal et al. [5], Lakshmikantham and Ćirić [6], and Harjani and Sadarangani [7].

In [2], Gnana Bhaskar and Lakshmikantham introduced the notions of mixed monotone mappings and a coupled fixed point and proved some coupled fixed point theorems for mixed monotone mappings.

In [3], Nieto and Rodríguez-López studied some fixed point theorems for monotone nondecreasing mappings in partially ordered metric spaces. They proved the existence of a fixed point in partially ordered metric spaces and applied the obtained results to study a problem of ordinary differential equations.

In [6], Lakshmikantham and Ćirić introduced notions of a mixed $g$-monotone mapping and proved coupled coincidence and coupled common fixed point theorems for such nonlinear contractive mappings in partially ordered complete metric spaces. They defined the mixed $g$-monotone property as follows.

Let $(X, \leqslant)$ be a partially ordered set, and let $F: X \times X \rightarrow$ $X$ and $g: X \rightarrow X$. We say that $F$ has the mixed $g$ monotone property if $F$ is monotone $g$-nondecreasing in its first argument and is monotone $g$-nonincreasing in its second argument; that is, for any $x, y \in X$,

$$
\begin{aligned}
& x_{1}, x_{2} \in X, \quad g\left(x_{1}\right) \leqslant g\left(x_{2}\right) \Longrightarrow F\left(x_{1}, y\right) \leqslant F\left(x_{2}, y\right), \\
& y_{1}, y_{2} \in X, \quad g\left(y_{1}\right) \leqslant g\left(y_{2}\right) \Longrightarrow F\left(x, y_{1}\right) \geqslant F\left(x, y_{2}\right) .
\end{aligned}
$$

They proved the following theorem.

Theorem 2 (see [6, Theorem 2.1]). Let $(X, \leqslant)$ be a partially ordered set, and suppose that there is a metric $d$ on $X$ such that $(X, d)$ is a complete metric space. Assume that there is a function $\varphi:[0,+\infty) \rightarrow[0,+\infty)$ with $\varphi(t)<t$ and $\lim _{r \rightarrow t^{+}} \varphi(r)<t$ for each $t>0$, and also suppose that $F: X \times X \rightarrow X$ and $g: X \rightarrow X$ are such that $F$ has the mixed $g$-monotone property and

$$
\begin{aligned}
& d(F(x, y), F(u, v)) \\
& \quad \leqslant \varphi\left(\frac{d(g(x), g(u)+d(g(y), g(v)))}{2}\right),
\end{aligned}
$$

for all $x, y, u, v \in X$ for which $g(x) \leqslant g(u)$ and $g(y) \geqslant g(v)$.
Suppose $F(X \times X) \subseteq g(X), g$ is continuous and commutes with $F$, and also suppose that either

(a) $F$ is continuous or

(b) X has the following properties:

(i) if a nondecreasing sequence $\left\{x_{n}\right\} \rightarrow x$ in $X$, then $x_{n} \leqslant x$ for all $n$;

(ii) if a nonincreasing sequence, $\left\{y_{n}\right\} \rightarrow y$ in $X$, then $y \leqslant y_{n}$ for all $n$.

If there exist $x_{0}, y_{0} \in X$ such that $g\left(x_{0}\right) \leqslant F\left(x_{0}, y_{0}\right)$ and $g\left(y_{0}\right) \geqslant F\left(y_{0}, x_{0}\right)$, then there exist $x, y \in X$ such that $g(x)=$ $F(x, y)$ and $g(y)=F(y, x)$. That is, $F$ and $g$ have a coupled coincidence point.

Coupled coincidence and coupled common fixed point theorems for mixed $g$-monotone single valued mappings can be applied for solving solutions of some ordinary differential equations, so there are many authors who pay their attention for the existence problem of coupled coincidence and coupled common fixed point theorems; see more detail in [6, 8-11].

In [8], Abbas et al. studied coupled coincidence point and common fixed point theorems for a pair of multivalued and single valued mappings which satisfy a generalized contractive condition in complete metric spaces. In [12], Huang and Fang introduced a class of multivalued mixed increasing operators in Banach spaces and proved some new fixed point and coupled fixed point theorems. In [13], Choudhury and Metiya proved some fixed point theorems for multivalued and single valued mappings in partially ordered metric spaces. In [14], Yin and Guo introduced the new notion of $g$-monotone mapping and proved some fixed point theorems for multivalued and single valued $g$-increasing mappings in partially ordered metric spaces. The mappings considered in [14] are assumed to satisfy certain metric inequalities which are established by an altering distance function. The main results of [14] extended and improved those of Choudhury and Metiya [13].

Motivated and inspired by these works, we introduce new classes of mixed monotone multivalued mapping in partially ordered metric spaces and prove some existence theorems for coupled fixed point, coupled coincidence point, and coupled common fixed point.

Next, we define two types of relations between the two sets and use these relations to introduce new types of multivalued mappings and show some relationships between these classes of mappings.

Definition 3. Let $(X, \leqslant)$ be a partially ordered set and let $A, B$ be two nonempty subsets of $X$. Then we denote (i) $A \stackrel{(I)}{<} B$ if for each $a \in A$ there exists $b \in B$ such that
$a<b ;$

(ii) $A \stackrel{(S)}{<} B$ if for each $b \in B$ there exists $a \in A$ such that $a<b$. 
Definition 4 . Let $(X, \leqslant)$ be a partially ordered set, and let $F$ : $X \times X \rightarrow 2^{X}$ and $g: X \rightarrow X$. We say that $F$ is mixed $g$-monotone of type $(A)$ if for any $x, y \in X$

$$
\begin{aligned}
& x_{1}, x_{2} \in X, \quad g\left(x_{1}\right)<g\left(x_{2}\right) \Longrightarrow F\left(x_{1}, y\right) \stackrel{(I)}{<} F\left(x_{2}, y\right), \\
& y_{1}, y_{2} \in X, \quad g\left(y_{1}\right)<g\left(y_{2}\right) \Longrightarrow F\left(x, y_{2}\right) \stackrel{(I)}{<} F\left(x, y_{1}\right) .
\end{aligned}
$$

Definition 5 . Let $(X, \leqslant)$ be a partially ordered set, let $F: X \times$ $X \rightarrow 2^{X}$ be a multivalued mapping, and let $g: X \rightarrow X$. We say that $F$ is mixed $g$-monotone of type $(B)$ if, for any $x_{1}, x_{2}, y_{1}, y_{2} \in X$,

$$
\begin{gathered}
g\left(x_{1}\right)<g\left(x_{2}\right), g\left(y_{1}\right)>g\left(y_{2}\right) \\
\Longrightarrow F\left(x_{1}, y_{1}\right) \stackrel{(I)}{<} F\left(x_{2}, y_{2}\right) .
\end{gathered}
$$

The following proposition gives a relation between multivalued mappings of these two types.

Proposition 6. Let $(X, \leqslant)$ be a partially ordered set and $d a$ metric on $X, F: X \times X \rightarrow 2^{X}$ and $g: X \rightarrow X$. If $F$ is mixed $g$-monotone of type $(A)$, then it is of type $(B)$.

Proof. Let $x_{1}, x_{2}, y_{1}, y_{2} \in X$ such that $g\left(x_{1}\right)<g\left(x_{2}\right)$ and $g\left(y_{1}\right)>g\left(y_{2}\right)$. Since $F$ is mixed $g$-monotone of type $(A)$, we have $F\left(x_{1}, y_{1}\right) \stackrel{(I)}{<} F\left(x_{2}, y_{1}\right)$ and $F\left(x_{2}, y_{1}\right) \stackrel{(I)}{<} F\left(x_{2}, y_{2}\right)$. This implies that $F\left(x_{1}, y_{1}\right) \stackrel{(I)}{<} F\left(x_{2}, y_{2}\right)$.

The converse of the above proposition is not true in general as seen in the following example.

Example 7. Let $X=[1, \infty)$, and let $\leqslant$ be a usual partially ordered on $X$; that is, $x \leqslant y$ if and only if $y-x \geqslant 0$. Let $F: X \times X \rightarrow C B(X)$ and $g: X \rightarrow X$ be defined by

$$
F(x, y)= \begin{cases}{[1,4],} & \text { if }(x, y)=(1,1), \\ \left\{1+\frac{2}{3}\left(x+\frac{1}{y}\right)\right\}, & \text { otherwise }\end{cases}
$$

and let $g(x)=x$. It is easy to show that $F$ is mixed $g$ monotone of type $(B)$, but it is not of type $(A)$. Consider $y=1$, $x_{1}=1$, and $x_{2}=2$, we have $F\left(x_{1}, 1\right)=F(1,1)=[1,4]$ and $F\left(x_{2}, 1\right)=F(2,1)=\{1+(2 / 3)(2+1)\}=\{3\}$. It follows that $F\left(x_{1}, 1\right) \stackrel{(I)}{\nless} F\left(x_{2}, 1\right)$. Hence, $F$ is not mixed $g$-monotone of type $(A)$.

\section{Main Results}

In this section, we prove the existence of a coupled fixed points of mixed $g$-monotone multivalued mappings of types $(A)$ and $(B)$.

Theorem 8. Let $(X, \leqslant)$ be a partially ordered set, and suppose that there is a metric $d$ on $X$ such that $(X, d)$ is a complete metric space. Suppose $F: X \times X \rightarrow C B(X)$ and $g: X \rightarrow X$ are such that $F$ is mixed g-monotone of type $(B)$. Assume that there is a function $\varphi:[0, \infty) \rightarrow[0, \infty)$ with $\varphi(t)<t$ and $\lim _{r \rightarrow t^{+}} \varphi(r)<t$ for each $t>0$ and

$$
\begin{aligned}
& \delta(F(x, y), F(u, v)) \\
& \quad \leqslant \varphi\left(\frac{d(g(x), g(u))+d(g(y), g(v))}{2}\right),
\end{aligned}
$$

for all $x, y, u, v \in X$ for which $g(x)>g(u)$ and $g(y)<g(v)$. Suppose that $F(X \times X) \subseteq g(X), g(X)$ is a complete subset of $X$, and suppose that

(a) there exist $x_{0}, y_{0} \in X$ such that

$$
\left\{g\left(x_{0}\right)\right\} \stackrel{(I)}{<} F\left(x_{0}, y_{0}\right), \quad\left\{g\left(y_{0}\right)\right\} \stackrel{(S)}{>} F\left(y_{0}, x_{0}\right),
$$

(b) X has the following properties:

(i) if an increasing sequence $\left\{x_{n}\right\} \rightarrow x$, then $x_{n}<x$ for all $n$;

(ii) if a decreasing sequence $\left\{y_{n}\right\} \rightarrow y$, then $y<y_{n}$ for all $n$.

Then there exist $x, y \in X$ such that

$$
g(x) \in F(x, y), \quad g(y) \in F(y, x) .
$$

Proof. Let $x_{0}, y_{0} \in X$ be such that $\left\{g\left(x_{0}\right)\right\} \stackrel{(I)}{<} F\left(x_{0}, y_{0}\right)$ and $\left\{g\left(y_{0}\right)\right\} \stackrel{(S)}{>} F\left(y_{0}, x_{0}\right)$. Since $F(X \times X) \subseteq g(X)$, it follows that there exist $x_{1}, y_{1} \in X$ such that $g\left(x_{1}\right) \in F\left(x_{0}, y_{0}\right), g\left(y_{1}\right) \in$ $F\left(y_{0}, x_{0}\right)$ and $g\left(x_{0}\right)<g\left(x_{1}\right), g\left(y_{0}\right)>g\left(y_{1}\right)$. Since $F$ is mixed $g$-monotone of type $(B)$, we obtain

$$
F\left(x_{0}, y_{0}\right) \stackrel{(I)}{<} F\left(x_{1}, y_{1}\right), \quad F\left(y_{1}, x_{1}\right) \stackrel{(I)}{<} F\left(y_{0}, x_{0}\right) .
$$

Again from $F(X \times X) \subseteq g(X)$, we can choose $x_{2}, y_{2} \in X$ such that $g\left(x_{2}\right) \in F\left(x_{1}, y_{1}\right), g\left(y_{2}\right) \in F\left(y_{1}, x_{1}\right)$ and $g\left(x_{1}\right)<$ $g\left(x_{2}\right), g\left(y_{1}\right)>g\left(y_{2}\right)$. By continuing this process, we obtain sequences $\left\{g\left(x_{n}\right)\right\}$ and $\left\{g\left(y_{n}\right)\right\}$ in $X$ such that

$$
\begin{aligned}
g\left(x_{n+1}\right) \in & F\left(x_{n}, y_{n}\right), \quad g\left(y_{n+1}\right) \in F\left(y_{n}, x_{n}\right), \quad \forall n \geqslant 0 \\
& g\left(x_{0}\right)<g\left(x_{1}\right)<\cdots<g\left(x_{n}\right)<\cdots, \\
& g\left(y_{0}\right)>g\left(y_{1}\right)>\cdots>g\left(y_{n}\right)>\cdots
\end{aligned}
$$

Put

$$
\alpha_{n}=d\left(g\left(x_{n}\right), g\left(x_{n+1}\right)\right)+d\left(g\left(y_{n}\right), g\left(y_{n+1}\right)\right), \quad \forall n \geqslant 0 \text {. }
$$

We show that

$$
\alpha_{n} \leqslant 2 \varphi\left(\frac{\alpha_{n-1}}{2}\right)
$$


Since $g\left(x_{n-1}\right)<g\left(x_{n}\right)$ and $g\left(y_{n-1}\right)>g\left(y_{n}\right)$, from (14) and (10) we have

$$
\begin{aligned}
d & \left(g\left(x_{n}\right), g\left(x_{n+1}\right)\right) \\
& \leqslant \delta\left(F\left(x_{n-1}, y_{n-1}\right), F\left(x_{n}, y_{n}\right)\right) \\
& \leqslant \varphi\left(\frac{d\left(g\left(x_{n-1}\right), g\left(x_{n}\right)\right)+d\left(g\left(y_{n-1}\right), g\left(y_{n}\right)\right)}{2}\right) \\
& =\varphi\left(\frac{\alpha_{n-1}}{2}\right) .
\end{aligned}
$$

Similarly, we have

$$
\begin{aligned}
& d\left(g\left(y_{n}\right), g\left(y_{n+1}\right)\right) \\
& \quad \leqslant \delta\left(F\left(y_{n-1}, x_{n-1}\right), F\left(y_{n}, x_{n}\right)\right) \\
& \quad \leqslant \varphi\left(\frac{d\left(g\left(y_{n-1}\right), g\left(y_{n}\right)\right)+d\left(g\left(x_{n-1}\right), g\left(x_{n}\right)\right)}{2}\right) \\
& \quad=\varphi\left(\frac{\alpha_{n-1}}{2}\right) .
\end{aligned}
$$

Adding (19) and (20), we obtain (18).

Since $\varphi(t)<t$ for $t>0$, it follows From (18) that a sequence $\left\{\alpha_{n}\right\}$ is monotone decreasing. Therefore, there is some $\alpha \geqslant 0$ such that

$$
\lim _{n \rightarrow \infty} \alpha_{n}=\alpha .
$$

We show that $\alpha=0$. Suppose, to the contrary, that $\alpha>0$. Then, by taking the limit as $n \rightarrow \infty$ on both sides of (18), we have

$$
\begin{aligned}
\alpha & =\lim _{n \rightarrow \infty} \alpha_{n} \leqslant 2 \lim _{n \rightarrow \infty} \varphi\left(\frac{\alpha_{n-1}}{2}\right) \\
& =2 \lim _{\alpha_{n} \rightarrow \alpha^{+}} \varphi\left(\frac{\alpha_{n-1}}{2}\right)<2 \frac{\alpha}{2}=\alpha,
\end{aligned}
$$

which is a contradiction. Thus, $\alpha=0$; that is,

$$
\lim _{n \rightarrow \infty}\left[d\left(g\left(x_{n}\right), g\left(x_{n+1}\right)\right)+d\left(g\left(y_{n}\right), g\left(y_{n-1}\right)\right)\right]=0 \text {. }
$$

Now we prove that $\left\{g\left(x_{n}\right)\right\}$ and $\left\{g\left(y_{n}\right)\right\}$ are Cauchy sequences. Suppose, to the contrary, that at least one of $\left\{g\left(x_{n}\right)\right\}$ or $\left\{g\left(y_{n}\right)\right\}$ is not a Cauchy sequence. Then there exists an $\varepsilon>0$ and two subsequences of integers $\{l(k)\},\{m(k)\}$, $m(k)>l(k) \geqslant k$ with

$$
\begin{aligned}
r_{k}= & d\left(g\left(x_{l(k)}\right), g\left(x_{m(k)}\right)\right) \\
& +d\left(g\left(y_{l(k)}\right), g\left(y_{m(k)}\right)\right) \geqslant \varepsilon \quad \text { for } k \in \mathbb{N} .
\end{aligned}
$$

We may also assume that

$$
d\left(g\left(x_{l(k)}\right), g\left(x_{m(k)-1}\right)\right)+d\left(g\left(y_{l(k)}\right), g\left(y_{m(k)-1}\right)\right)<\varepsilon
$$

by choosing $m(k)$ to be the smallest number exceeding $l(k)$ for which (24) holds. From (24) and (25) and by the triangle inequality, we have

$$
\begin{aligned}
\varepsilon \leqslant & r_{k} \leqslant d\left(g\left(x_{l(k)}\right), g\left(x_{m(k)-1}\right)\right) \\
& +d\left(g\left(x_{m(k)-1}\right), g\left(x_{m(k)}\right)\right) \\
& +d\left(g\left(y_{l(k)}\right), g\left(y_{m(k)-1}\right)\right) \\
& +d\left(g\left(y_{m(k)-1}\right), g\left(y_{m(k)}\right)\right) \\
= & d\left(g\left(x_{l(k)}\right), g\left(x_{m(k)-1}\right)\right) \\
& +d\left(g\left(y_{l(k)}\right), g\left(y_{m(k)-1}\right)\right)+\alpha_{m(k)-1} \\
< & \varepsilon+\alpha_{m(k)-1} .
\end{aligned}
$$

By taking the limit as $k \rightarrow \infty$, we get

$$
\lim _{k \rightarrow \infty} r_{k}=\varepsilon
$$

By the triangle inequality, we have

$$
\begin{aligned}
r_{k}= & d\left(g\left(x_{l(k)}\right), g\left(x_{m(k)}\right)\right) \\
& +d\left(g\left(y_{l(k)}\right), g\left(y_{m(k)}\right)\right) \\
\leqslant & d\left(g\left(x_{l(k)}\right), g\left(x_{l(k)+1}\right)\right) \\
& +d\left(g\left(x_{l(k)+1}\right), g\left(x_{m(k)+1}\right)\right) \\
+ & d\left(g\left(x_{m(k)+1}\right), g\left(x_{m(k)}\right)\right) \\
+ & d\left(g\left(y_{l(k)}\right), g\left(y_{l(k)+1}\right)\right) \\
+ & d\left(g\left(y_{l(k)+1}\right), g\left(y_{m(k)+1}\right)\right) \\
+ & d\left(g\left(y_{m(k)+1}\right), g\left(y_{m(k)}\right)\right) \\
= & d\left(g\left(x_{l(k)}\right), g\left(x_{l(k)+1}\right)\right) \\
& \left.+d\left(g\left(y_{l(k)}\right), g\left(y_{l(k)+1}\right)\right)\right] \\
+ & {\left[d\left(g\left(x_{m(k)}\right), g\left(x_{m(k)+1}\right)\right)\right.} \\
& \left.+d\left(g\left(y_{m(k)}\right), g\left(y_{m(k)+1}\right)\right)\right] \\
+ & {\left[d\left(g\left(x_{l(k)+1}\right), g\left(x_{m(k)+1}\right)\right)\right.} \\
& \left.+d\left(g\left(y_{l(k)+1}\right), g\left(y_{m(k)+1}\right)\right)\right] .
\end{aligned}
$$

Hence,

$$
\begin{aligned}
r_{k} \leqslant & \alpha_{l(k)}+\alpha_{m(k)} \\
& +d\left(g\left(x_{l(k)+1}\right), g\left(x_{m(k)+1}\right)\right) \\
& +d\left(g\left(y_{l(k)+1}\right), g\left(y_{m(k)+1}\right)\right) .
\end{aligned}
$$


From (15) and (16), we have $g\left(x_{l(k)}\right)<g\left(x_{m(k)}\right)$ and $g\left(y_{l(k)}\right)>$ $g\left(y_{m(k)}\right)$. By (14) and (iii), we have

$$
\begin{aligned}
& d\left(g\left(x_{l(k)+1}\right), g\left(x_{m(k)+1}\right)\right) \\
& \quad \leqslant \delta\left(F\left(x_{l(k)}, y_{l(k)}\right), F\left(x_{m(k)}, y_{m(k)}\right)\right) \\
& \quad \leqslant \varphi\left(\frac{d\left(g\left(x_{l(k)}\right), g\left(x_{m(k)}\right)\right)+d\left(g\left(y_{l(k)}\right), g\left(y_{m(k)}\right)\right)}{2}\right) \\
& \quad=\varphi\left(\frac{r_{k}}{2}\right) .
\end{aligned}
$$

Similarly, we have

$$
\begin{aligned}
& d\left(g\left(y_{l(k)+1}\right), g\left(y_{m(k)+1}\right)\right) \\
& \quad \leqslant \delta\left(F\left(y_{l(k)}, x_{l(k)}\right), F\left(y_{m(k)}, x_{m(k)}\right)\right) \\
& \quad \leqslant \varphi\left(\frac{d\left(g\left(y_{l(k)}\right), g\left(y_{m(k)}\right)\right)+d\left(g\left(x_{l(k)}\right), g\left(x_{m(k)}\right)\right)}{2}\right) \\
& \quad=\varphi\left(\frac{r_{k}}{2}\right) .
\end{aligned}
$$

It follows from (30), (31), and (29) that

$$
r_{k} \leqslant \alpha_{l(k)}+\alpha_{m(k)}+2 \varphi\left(\frac{r_{k}}{2}\right)
$$

By using (23) and (27) together with the property of $\varphi$, we have

$$
\varepsilon \leqslant 2 \lim _{k \rightarrow \infty} \varphi\left(\frac{r_{k}}{2}\right)=2 \lim _{r_{k} \rightarrow \varepsilon^{+}} \varphi\left(\frac{r_{k}}{2}\right)<2 \frac{\varepsilon}{2}=\varepsilon
$$

which is a contradiction. Thus, $\left\{g\left(x_{n}\right)\right\}$ and $\left\{g\left(y_{n}\right)\right\}$ are Cauchy sequences. Since $g(X)$ is complete, there exist $x, y \in$ $X$ such that

$$
\lim _{n \rightarrow \infty} g\left(x_{n}\right)=g(x), \quad \lim _{n \rightarrow \infty} g\left(y_{n}\right)=g(y) .
$$

Finally, we claim $g(x) \in F(x, y)$ and $g(y) \in F(y, x)$.

From (34) and (ii), we obtain $g\left(x_{n}\right)<g(x)$, and $g\left(y_{n}\right)>$ $g(y)$, for all $n \geqslant 0$. By (iii), we have

$$
\begin{aligned}
& d\left(F(x, y), g\left(x_{n+1}\right)\right) \\
& \quad \leqslant \delta\left(F(x, y), F\left(x_{n}, y_{n}\right)\right) \\
& \quad \leqslant \varphi\left(\frac{d\left(g\left(x_{n}\right), g(x)\right)+d\left(g\left(y_{n}\right), g(y)\right)}{2}\right) .
\end{aligned}
$$

This implies by Lemma 1 and the property of $\varphi$ that $d(F(x, y), g(x))=0$. Hence, $g(x) \in F(x, y)$. Similarly, we can show that $g(y) \in F(y, x)$. Thus, $(x, y)$ is a coupled coincidence point of $F$ and $g$.
Example 9. Let $X=[1, \infty)$ and let $\leqslant$ be a usual partially ordered on $X$; that is, $x \leqslant y$ if and only if $y-x \geqslant 0$. Let $F: X \times X \rightarrow C B(X)$ and $g: X \rightarrow X$ be defined by

$$
F(x, y)= \begin{cases}{\left[1, \frac{4}{3}\right],} & \text { if }(x, y)=(1,1) \\ \left\{1+\frac{2}{9}\left(x+\frac{1}{y}\right)\right\}, & \text { otherwise }\end{cases}
$$

and let $g(x)=x$. It is easy to check that $F$ is a mixed $g$ monotone of type $(B)$. Now we prove that (10) holds. Let $x, y, u, v \in X$ such that $g(x)>g(u)$ and $g(y)<g(v)$. Then $x>u$ and $y<v$. So $(x, y) \neq(1,1)$ and $(u, v) \neq(1,1)$. And we have

$$
\begin{aligned}
\delta & F(x, y), F(u, v)) \\
& =\delta\left(\left\{1+\frac{2}{9}\left(x+\frac{1}{y}\right)\right\},\left\{1+\frac{2}{9}\left(u+\frac{1}{v}\right)\right\}\right) \\
& =\left|1+\frac{2}{9}\left(x+\frac{1}{y}\right)-1-\frac{2}{9}\left(u+\frac{1}{v}\right)\right| \\
& =\frac{2}{9}\left|(x-u)+\left(\frac{1}{y}-\frac{1}{v}\right)\right| \\
& \leqslant \frac{2}{9}\left(|x-u|+\left|\frac{1}{y}-\frac{1}{v}\right|\right) \\
& <\frac{2}{9}(|x-u|+|y-v|) \\
& \leqslant \frac{4}{9} \cdot \frac{1}{2}(|x-u|+|y-v|) \\
& \leqslant \varphi\left(\frac{d(x, u)+d(y, v)}{2}\right) \\
& =\varphi\left(\frac{d(g(x), g(u))+d(g(y), g(v))}{2}\right),
\end{aligned}
$$

where $\varphi(t)=(4 / 9) t$. By Theorem 8 , we obtain that $F$ has a coupled fixed point. Note that $(1,1)$ is a coupled fixed point of $F$.

The following results are obtained directly from Theorem 8 and Proposition 6.

Corollary 10. Let $(X, \leqslant)$ be a partially ordered set, and suppose that there is a metric $d$ on $X$ such that $(X, d)$ is a complete metric space. Suppose that $F: X \times X \rightarrow C B(X)$ and $g: X \rightarrow X$ are such that $F$ is a mixed $g$-monotone of type $(A)$. Assume that there is a function $\varphi:[0, \infty) \rightarrow[0, \infty)$ with $\varphi(t)<t$ and $\lim _{r \rightarrow t^{+}} \varphi(r)<t$ for each $t>0$ and

$$
\begin{aligned}
& \delta(F(x, y), F(u, v)) \\
& \quad \leqslant \varphi\left(\frac{d(g(x), g(u))+d(g(y), g(v))}{2}\right),
\end{aligned}
$$


for all $x, y, u, v \in X$ for which $g(x)>g(u)$ and $g(y)<g(v)$. Suppose that $F(X \times X) \subseteq g(X)$, that $g(X)$ is a complete subset of $X$; suppose that

(a) there exist $x_{0}, y_{0} \in X$ such that

$$
\left\{g\left(x_{0}\right)\right\} \stackrel{(I)}{<} F\left(x_{0}, y_{0}\right), \quad\left\{g\left(y_{0}\right)\right\} \stackrel{(S)}{>} F\left(y_{0}, x_{0}\right),
$$

(b) X has the following properties:

(i) if an increasing sequence $\left\{x_{n}\right\} \rightarrow x$, then $x_{n}<x$ for all $n$;

(ii) if a decreasing sequence $\left\{y_{n}\right\} \rightarrow y$, then $y<y_{n}$ for all $n$.

Then there exist $x, y \in X$ such that

$$
g(x) \in F(x, y), \quad g(y) \in F(y, x) .
$$

Note that the contractive condition (38) is weaker than the condition (5) in [6].

Theorem 11. In addition to the hypotheses of Theorem 8 and Corollary 10, if one of the following conditions holds:

(a) $F$ and $g$ are w-compatible, $\left\{g^{n}(x)\right\}$ is an increasing sequence which converges to $u,\left\{g^{n}(y)\right\}$ is a decreasing sequence which converges to $v$ for some $(x, y) \in$ $C(F, g), u, v \in X$, and $g$ is continuous at $u$ and $v$,

(b) $g$ is F-weakly commuting for some $(x, y) \in C(F, g)$, $g^{2}(x)=g(x)$, and $g^{2}(y)=g(y)$,

(c) $g$ is continuous at $x$ and $y$ for some $(x, y) \in C(F, g)$; and $\lim _{n \rightarrow \infty} g^{n}(u)=x, \lim _{n \rightarrow \infty} g^{n}(v)=y$ for some $u, v \in X$,

(d) $\{(g(x), g(y)):(x, y) \in C(F, g)\}$ is singleton subset of $C(F, g)$.

Then $F$ and $g$ have a coupled common fixed point.

Proof. By Theorem $8, F$ and $g$ have a coupled coincidence point $(x, y) \in X \times X$. Suppose that (a) holds. Then $\left\{g^{n}(x)\right\}$ is an increasing sequence which converges to $u$, and $\left\{g^{n}(y)\right\}$ is a decreasing sequence which converges to $v$ for some $(x, y) \in$ $C(F, g), u, v \in X$. Hence, $g^{n}(x)<u$ and $g^{n}(y)>v$ for all $n \geqslant 1$. Since $g$ is continuous at $u$ and $v$, we have that $u$ and $v$ are fixed points of $g$; that is, $u=g(u)$ and $v=g(v)$. As $F$ and $g$ are $w$-compatible, $\left(g^{n}(x), g^{n}(y)\right) \in C(F, g)$ for all $n \geqslant 1$ and $g^{n}(x) \in F\left(g^{n-1}(x), g^{n-1}(y)\right), g^{n}(y) \in F\left(g^{n-1}(y), g^{n-1}(x)\right)$. Using (10), we obtain

$$
\begin{aligned}
d(g(u), F(u, v)) & \leqslant \\
\leqslant & d\left(g(u), g^{n}(x)\right)+d\left(g^{n}(x), F(u, v)\right) \\
\leqslant & d\left(g(u), g^{n}(x)\right) \\
& +\delta\left(F\left(g^{n-1}(x), g^{n-1}(y)\right), F(u, v)\right) \\
\leqslant & d\left(g(u), g^{n}(x)\right) \\
& +\varphi\left(\frac{d\left(g^{n-1}(x), u\right)+d\left(g^{n-1}(y), v\right)}{2}\right) .
\end{aligned}
$$

By taking limit as $n \rightarrow \infty$ and using the property of $\varphi$, we obtain $d(g(u), F(u, v))=0$, and hence $g(u) \in F(u, v)$. Similarly, we can show that $g(v) \in F(v, u)$. Consequently, $u=g(u) \in F(u, v)$ and $v=g(v) \in F(v, u)$. Hence, $(u, v)$ is a coupled common fixed point of $F$ and $g$. Suppose that (b) holds. That is $g$ is $F$-weakly commuting, $g^{2}(x)=g(x)$, and $g^{2}(y)=g(y)$ for some $(x, y) \in C(F, g)$. Then $g(x)=g^{2}(x) \epsilon$ $F(g(x), g(y))$, and $g(y)=g^{2}(y) \in F(g(y), g(x))$. Hence, $(g(x), g(y))$ is a coupled common fixed point of $F$ and $g$. Suppose now that (c) holds. Then there exists $(x, y) \in C(F, g)$ such that $g$ is continuous at $x$ and $y$ and $\lim _{n \rightarrow \infty} g^{n}(u)=x$, $\lim _{n \rightarrow \infty} g^{n}(v)=y$ for some $u, v \in X$. By the continuity of $g$ at $x$ and $y$, we get $x=g(x) \in F(x, y)$ and $y=g(y) \in F(y, x)$. Hence, $(x, y)$ is coupled common fixed point of $F$ and $g$. Finally, suppose that (d) holds. Let $\{(g(x), g(y)):(x, y) \in$ $C(F, g)\}=\left\{\left(g\left(x_{0}\right), g\left(y_{0}\right)\right)\right\} \subseteq C(F, g)$. Then $\left(g\left(x_{0}\right), g\left(y_{0}\right)\right) \in$ $C(F, g)$. Hence, $\left(g\left(x_{0}\right), g\left(y_{0}\right)\right)$ is a coupled common fixed point of $F$ and $g$.

\section{Acknowledgment}

This work was supported by Chiang Mai University, Chiang Mai, Thailand.

\section{References}

[1] A. C. M. Ran and M. C. B. Reurings, "A fixed point theorem in partially ordered sets and some applications to matrix equations," Proceedings of the American Mathematical Society, vol. 132, no. 5, pp. 1435-1443, 2004.

[2] T. Gnana Bhaskar and V. Lakshmikantham, "Fixed point theorems in partially ordered metric spaces and applications," Nonlinear Analysis: Theory, Methods \& Applications, vol. 65, no. 7, pp. 1379-1393, 2006.

[3] J. J. Nieto and R. Rodríguez-López, "Contractive mapping theorems in partially ordered sets and applications to ordinary differential equations," Order, vol. 22, no. 3, pp. 223-239, 2005.

[4] J. J. Nieto and R. Rodríguez-López, "Existence and uniqueness of fixed point in partially ordered sets and applications to ordinary differential equations," Acta Mathematica Sinica, vol. 23, no. 12, pp. 2205-2212, 2007.

[5] R. P. Agarwal, M. A. El-Gebeily, and D. O’Regan, "Generalized contractions in partially ordered metric spaces," Applicable Analysis, vol. 87, no. 1, pp. 109-116, 2008.

[6] V. Lakshmikantham and L. Ćirić, "Coupled fixed point theorems for nonlinear contractions in partially ordered metric spaces," Nonlinear Analysis: Theory, Methods \& Applications, vol. 70, no. 12, pp. 4341-4349, 2009.

[7] J. Harjani and K. Sadarangani, "Fixed point theorems for weakly contractive mappings in partially ordered sets," Nonlinear Analysis: Theory, Methods \& Applications, vol. 71, no. 7-8, pp. 34033410, 2009.

[8] M. Abbas, L. Ćirić, B. Damjanović, and M. A. Khan, "Coupled coincidence and common fixed point theorems for hybrid pair of mappings," Fixed Point Theory and Applications, vol. 2012, article 4, 2012.

[9] H. Aydi, E. Karapınar, and W. Shatanawi, "Coupled fixed point results for $(\psi, \varphi)$-weakly contractive condition in ordered partial metric spaces," Computers \& Mathematics with Applications, vol. 62 , no. 12, pp. 4449-4460, 2011. 
[10] V. Berinde, "Generalized coupled fixed point theorems for mixed monotone mappings in partially ordered metric spaces," Nonlinear Analysis: Theory, Methods \& Applications, vol. 74, no. 18, pp. 7347-7355, 2011.

[11] B. S. Choudhury and N. Metiya, "Coincidence point theorems for a family of multivalued mappings in partially ordered metric spaces," Acta Universitatis Matthiae Belii, Series Mathematics, no. 2013, pp. 10-23, 2013.

[12] N.-J. Huang and Y.-P. Fang, "Fixed points for multi-valued mixed increasing operators in ordered Banach spaces with applications to integral inclusions," Journal of Analysis and its Applications, vol. 22, no. 2, pp. 399-410, 2003.

[13] B. S. Choudhury and N. Metiya, "Multivalued and singlevalued fixed point results in partially ordered metric spaces," Arab Journal of Mathematical Sciences, vol. 17, no. 2, pp. 135-151, 2011.

[14] J. Yin and T. Guo, "Some fixed point results for a class of $g$ monotone increasing multi-valued mappings," Arab Journal of Mathematical Sciences, vol. 19, no. 1, pp. 35-47, 2013. 


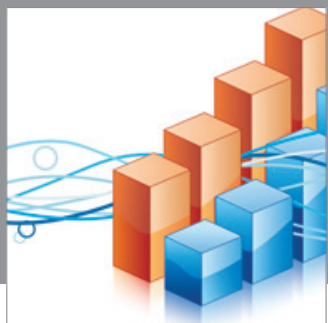

Advances in

Operations Research

mansans

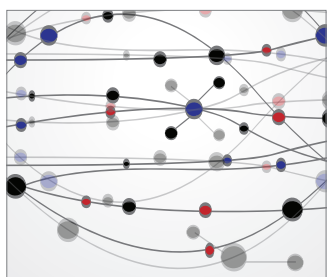

The Scientific World Journal
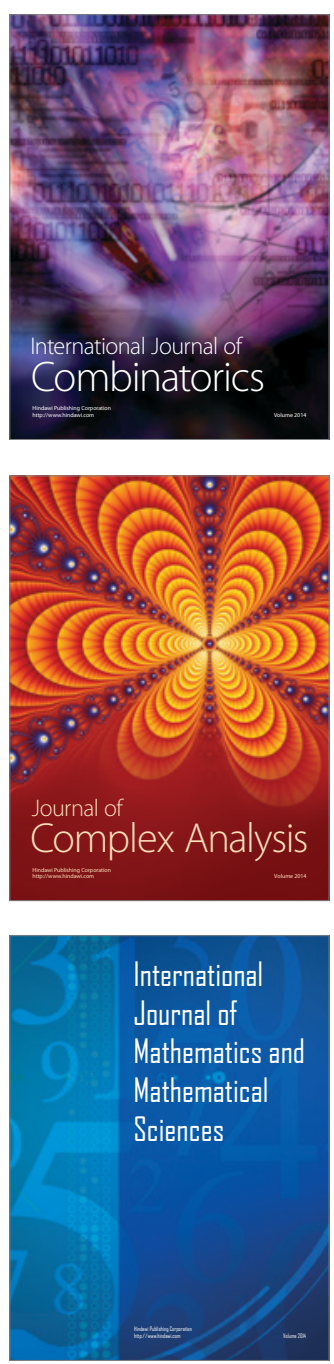
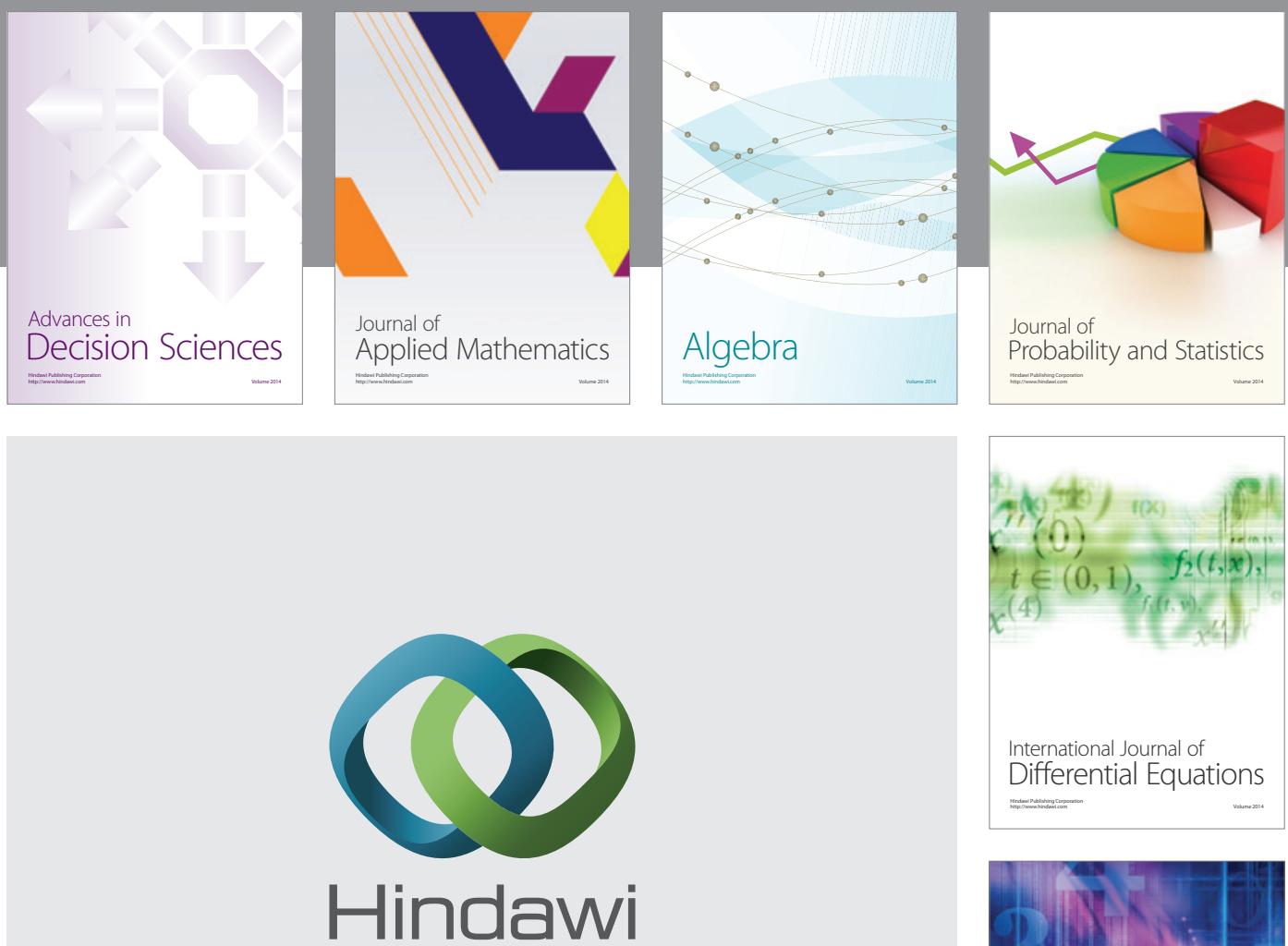

Submit your manuscripts at http://www.hindawi.com
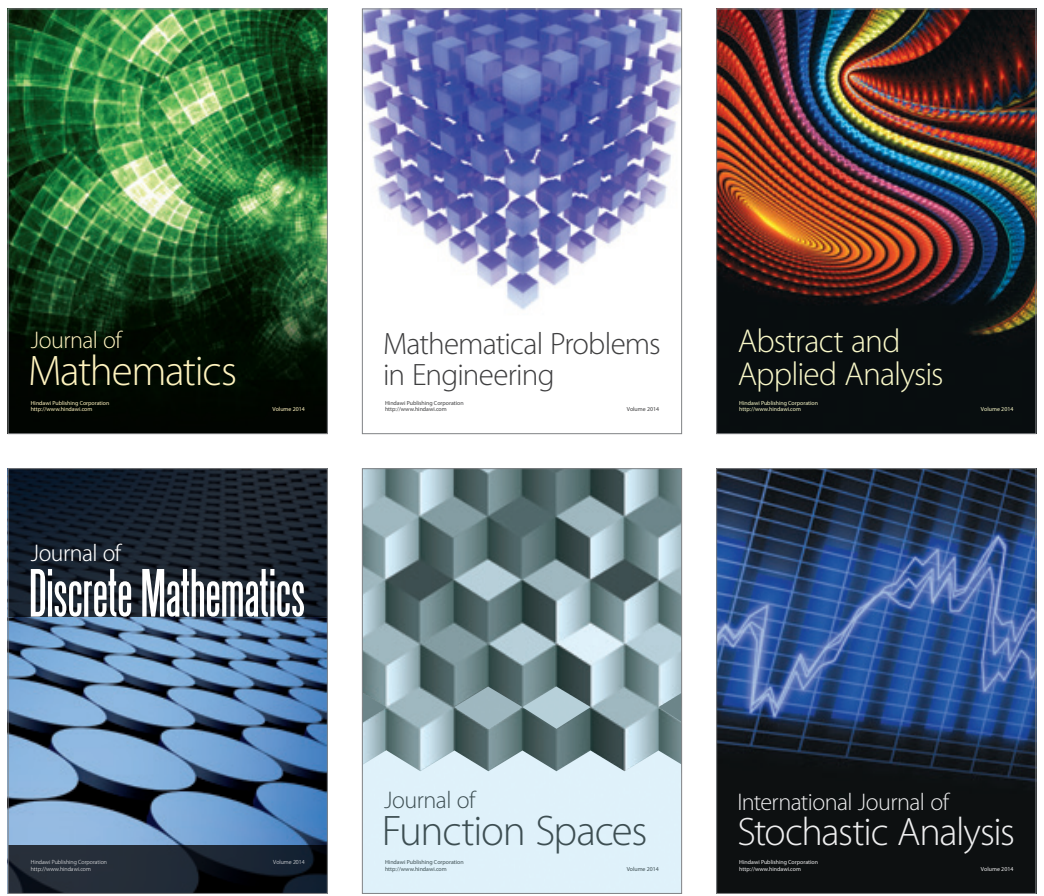

Journal of

Function Spaces

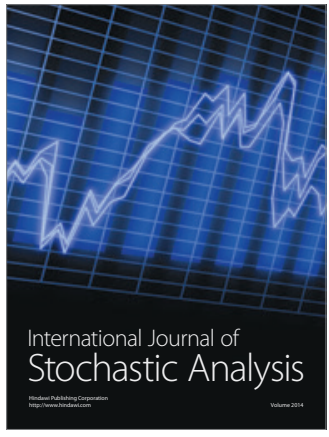

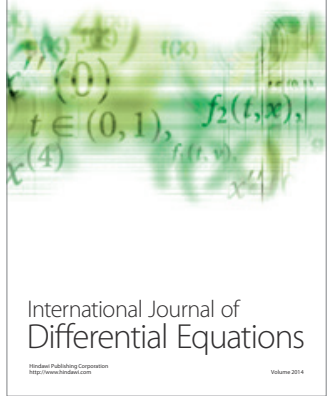
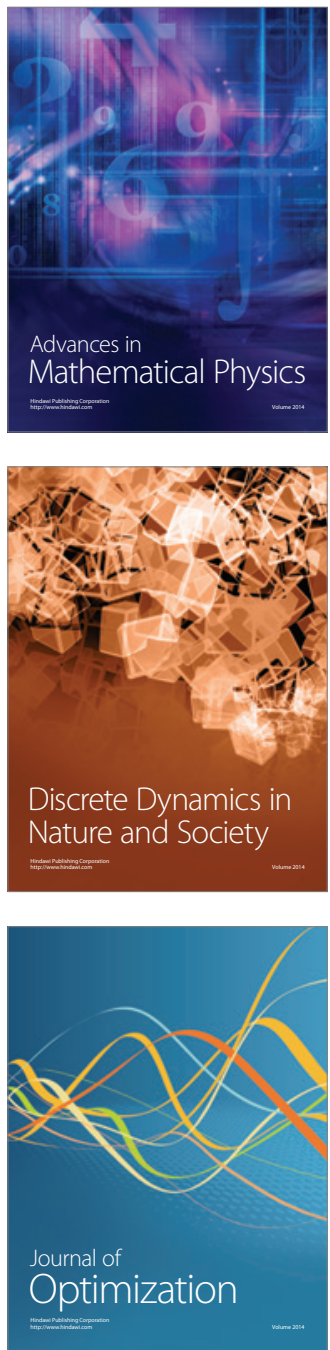